\title{
DIGLOSIA
}

Terakreditasi Sinta 3 | Volume 3 | Nomor 2 | Tahun 2020| Halaman 139-148

P-ISSN 2615-725X | E-ISSN 2615-8655

http://diglosiaunmul.com/index.php/diglosia/article/view/36

\section{KESALAHAN TERJEMAHAN DALAM SUBTITLE FILM THE HELPDAN HIDDEN FIGURES}

\section{Translation Errors in Movies Subtitles "The Help" and "Hidden Figures"}

\author{
Meliyanti Sihotang ${ }^{1, *}$, Shafruddin Tadjuddin ${ }^{2}$, Sri Harini Ekowati ${ }^{3}$ \\ ${ }^{1,2,3}$ Universitas Negeri Jakarta \\ 1.* Pos-el Korespondensi: meliyantisihotang_lt17s2@mahasiswa.unj.ac.id \\ ${ }^{2}$ Pos-el: shafruddin.ta@unj.ac.id \\ ${ }^{3}$ Pos-el: sriharini@unj.ac.id
}

\begin{abstract}
The aim of this study was to determine the cultural translation errors in aspect of gender and racial discrimination in movies subtitles The Help and Hidden Figures. This study used a qualitative approach and content analysis method by Krippendorff (2004). This qualitative study was in descriptive qualitative approach. While content analysis use was conversational analysis. Conversation in both movies subtitles were used as data of the study especially the conversation which was the part of gender and racial discrimination. The finding of this study was in form of cultural translation errors in conversation that contained gender and racial discrimination. The result showed, there were four kinds of cultural translation errors in aspect of gender and racial discrimination in movies subtitles The Help and Hidden Figures. They were (1) word choices translation errors; (2) number translation errors; (3) translation errors in cultural material; and (4) translation errors in comprehended SL in the text. All the errors found influeced information and message that delivered to the viewers.
\end{abstract}

Keywords: errors, translation, subtitle, race, gender

Abstrak: Tujuan penelitian ini untuk mengetahui kesalahan terjemahan budaya pada aspek diskriminasi gender dan ras dalam subtitle The Help dan Hidden Figures. Penelitian ini menggunakan pendekatan kualitatif dan metode analisis isi yang diperkenalkan oleh Krippendorff (2004). Pendekatan kualitatif pada penelitian ini adalah dengan menggunakan deskripsi kualitatif. Sementara analisis isi yang dimaksudkan adalah analisis isi percakapan. Adapun data yang digunakan dalam penelitian ini berasal percakapan yang mengandung unsur diskriminasi ras dan gender dalam subtitle The Help dan Hidden Figures. Temuan penelitian ini berupa kesalahan penerjemahan budaya pada percakapan yang mengandung diskriminasi ras dan gender. Berdasarkan temuan penelitian, peneliti menemukan empat bentuk kesalahan terjemahan budaya pada aspek diskriminasi gender dan ras dalam subtitle The Help dan Hidden Figures yakni (1) kesalahan terjemahan dalam pemilihan padanan kata; (2) kesalahan terjemahan bilangan; (3) kesalahan terjemahan budaya material; dan (4) kesalahan dalam memahami teks Tsu. Keempat kesalahan terjemahan yang ditemukan mempengaruhi informasi dan pesan yang disampaikan dalam terjemahan Tsa.

Kata kunci: kesalahan, terjemahan, subtitle, ras, gender

\section{A. PENDAHULUAN}

Sebuah film yang diproduksi dan ditayangkan akan membawa dampak pada penontonnya. Dampak tersebut berupa dampak sosial maupun dampak budaya. Dampak sosial berkaitan dengan pesan yang disampaikan lewat penokohan dan alur cerita pada film tersebut. Pesan tersebut dapat berupa kritik terhadap kondisi sosial yang terjadi di masyarakat maupun berupa dokumentasi sebuah peristiwa lewat penayangan autobiografi seorang tokoh atau narasi sebuah peristiwa sejarah. Sementara pertukaran budaya membawa dampak pada pemahaman akan perbedaan budaya dan terwujudnya toleransi terhadap perbedaan tersebut. Perbedaan yang mendasar dari sebuah film terdapat pada bahasa yang digunakan. Perbedaan memiliki pengaruh yang cukup 
signifikan pada film dan penontonnya. Bahasa memiliki peranan penting dalam penyampaian pesan yang terdapat dalam dialog para tokoh, serta sebagai jembatan untuk menjelaskan perbedaan sosiokultural. Hal inilah yang menyebabkan penerjemahan subtitle sebuah film dibutuhkan. Penerjemahan subtitle film dapat menjembatani perbedaan tersebut.

Meskipun penerjemahan subtitle sebuah film dapat menjadi jembatan antara penonton dengan apa yang ditonton, kesalahan penerjemahan subtitle dapat menjadi bumerang terhadap pesan yang disampaikan. Alih-alih penerjemahan subtitle yang mengandung unsur budaya membantu penonton mengerti, kesalahan penerjemahan budaya dapat memberikan kesalahpahaman bahkan kesalahan informasi. Hal inilah yang mendorong penulis untuk melakukan penelitian mengenai kesalahan penerjemahan budaya.

Analisis kesalahan penerjemahan budaya banyak dibahas secara umum namun analisis penerjemahan budaya spesifik tidak banyak dijumpai seperti penerjemahan budaya yang berkaitan dengan diskriminasi gender dan Ras. Hal ini yang mendorong penulis untuk mengetahui kesalahan terjemahan budaya yang mengandung unsur diskriminasi ras dan gender pada subtitle film The Help dan Hidden Figures. Adapun tujuan penelitian ini adalah untuk mengetahui kesalahan yang terdapat dalam terjemahan budaya pada aspek diskriminasi ras dan gender dalam subtitle film The Help dan Hidden Figures. Adapun pertanyaan yang akan dibahas dalam artikel ini yakni 'apa kesalahan yang terdapat dalam terjemahan budaya pada aspek diskriminasi ras dan gender dalam subtitle film The Help dan Hidden Figures.'

Menurut Kramsch (2008) budaya adalah produk suatu masyarakat. Sementara Geng (2013) menyatakan bahwa budaya adalah keseluruhan hidup masyarakat yang dapat diamati lewat interaksi dan karya yang dihasilkannya. Budaya bukanlah sesuatu yang tercipta dalam jangka waktu yang singkat. Kebudayaan tercipta dan diturunkan dalam periode yang lama dari satu generasi ke generasi lainnya (Pourkalhor \& Esfandiari, 2017). Sehingga dapat disimpulkan bahwa kebudayaan merupakan sesuatu yang berasal dan berkembang dalam masyarakat dalam waktu yang lama.

Budaya dan penerjemahan adalah dua hal yang tak dapat dipisahkan. Kedua bahasa ini membawa budaya masingmasing di dalamnya. Penerjemahan terhubung dengan dua bahasa yakni bahasa sumber (Bsu) dan bahasa sasaran (Bsa) memiliki komponen budaya di dalamnya Komponen budaya tersebut dapat tertuang dalam bahasa yang diterjemahkan. Komponen tersebut dapat berupa komponen yang terlihat secara konkret (material) dan komponen normatif. Budaya-budaya inilah yang nantinya ditransfer ke dalam budaya masyarakat sasaran yang membaca teks atau menonton film yang subtitle-nya diterjemahkan. Meskipun pada prosesnya budaya-budaya ini akan mengalami proses transfer, adaptasi maupun proses akulturasi namun tujuan penting dalam penerjemahan ini adalah membuat pembaca memahami perbedaan budayabudaya tersebut meskipun pada akhirnya membuat pembaca memiliki toleransi dalam menyikapi perbedaan budaya.

Terjemahan dapat didefinisikan sebagai upaya penggantian pesan dari Bsu ke dalam Bsa secara struktural (Newmark, 1986). Penggantian pesan ini dilakukan dengan tujuan komunikatif (Hatim \& Munday, 2013). Berbeda dengan Sokolovsky (2010) mendefinisikan penerjemahan sebagai proses, proses dan hasil, komunikasi dan skill. Proses yang dimaksudkan adalah kegiatan penerjemahan itu sendiri yang menghasilkan terjemahan yang dapat 
dibaca oleh publik. Sementara skill dan komunikasi berkaitan dengan kemampuan penerjemahan dalam menerjemahkan sebuah teks yang dapat mengomunikasikan pesan pengarang kepada pembaca. Sehingga dapat disimpulkan penerjemahan tersebut adalah proses pengalihan pesan dari Bsu ke dalam Bsa.

Menurut Newmark

penerjemahan budaya dapat dilihat dari lima kategori, Pertama ekologi yakni yang berhubungan dengan kondisi alam, flora fauna, iklim dan sebagainya. Kedua kebudayaan material berupa pakaian, alat transportasi, rumah, makanan dan lainlain. Ketiga kebudayaan sosial seperti liburan, dan pekerjaan. Keempat kebudayaan yang berupa sistem organisasi, sistem kepercayaan, ritual dan adat istiadat. Pada kategori keempat terdapat pembagian kelas, kekuasaan serta hierarki dalam masyarakat. Kategori terakhir berhubungan dengan kebiasaan dan gerak tubuh. Kelima kategori ini banyak ditemukan dalam menganalisis terjemahan budaya dan kesalahan terjemahan budaya secara umum seperti yang dilakukan oleh Naserly (2017) dalam menganalisis terjemahan subtitle Date Night. Selain itu terdapat juga penerjemahan subtitle film yang dipengaruhi oleh budaya cina yang dibahasa secara umum pula oleh (Guo, 2012). Akan tetapi jika diperiksa secara rinci, hanya sedikit penelitian yang membahas mengenai kategori-kategori budaya di atas secara rinci, khususnya sistem nilai yang dianut dan pengaruhnya pada tatanan sosial masyarakat seperti halnya diskriminasi gender dan ras dalam masyarakat.

Jandt berpendapat bahwa inferioritas dan superioritaslah yang mengakibatkan terjadinya diskriminasi dalam masyarakat (dalam Arsi \& Sobur, 2019). Dominasi terhadap kelompok minoritas baik dalam aspek jumlah maupun dalam aspek pengaruh tak dapat dipungkiri mengakibatkan terjadinya diskriminasi. Diskriminasi inilah yang akan mengakibatkan gesekan di dalam masyarakat yang akan membawa dampak yang kurang baik terhadap tatanan sosial dimasyarakat. Diskriminasi dalam masyarakat secara umum terjadi akibat perbedaan fisik, keyakinan, peran, dan banyak lagi. Akan tetapi tiap masyarakat budaya memiliki perbedaan dalam cara melakukan diskriminasi.

Dalam artikel penelitian ini, fokus penelitian adalah mengenai diskriminasi ras dan gender dalam masyarakat. Nurmila (2015) menyatakan keberpihakan terhadap pria dalam sebuah kehidupan masyarakat budaya mengakibatkan terjadinya diskriminasi gender. Diskriminasi gender muncul ribuan tahun lalu akibat budaya patriarki yang dianut dalam masyarakat. Hal ini diperparah dengan keyakinan yang dianut juga menempatkan perempuan sebagai warga kelas dua. Diskriminasi gender mengakibatkan perempuan memiliki ruang gerak yang terbatas baik dalam bidang profesional seperti pekerjaan dan juga dalam ruang privasi seperti hak untuk memilih pasangan dalam pernikahan. Kebebasan perempuan pun jadi harga yang sangat mahal. Selain itu dominasi gender mengakibatkan perempuan sering mengalami kekerasan baik kekerasan verba maupun fisik.

Sementara diskriminasi ras terjadi akibat perbedaan fisik dalam masyarakat (Clair \& Denis, 2015). Dalam masyarakat Eropa dan Amerika bahkan Afrika selatan, diskriminasi terjadi akibat perbedaan warna kulit yakni putih dan hitam. Warga kelas satu pada masa itu diduduki oleh warga kulit putih keturunan imigran Eropa, Sementara warga kelas dua adalah warga kulit Hitam. Di Indonesia sendiri diskriminasi terjadi pada masa kolonial Belanda yang membagi masyarakat dalam kelas-kelas sosial yakni warga keturunan Eropa menjadi warga kelas satu, warga kelas dua berasal dari keturunan asing seperti China dan Arab, warga kelas tiga diisi kaum bangsawan dan yang terakhir adalah rakyat jelata yang berasal dari 
pribumi. Diskriminasi ini membawa dampak buruk bagi masyarakat yang berbeda sebagai masyarakat yang dikuasai karena berpengaruh dalam mendapatkan kesempatan untuk mendapatkan kesejahteraan. Mereka dibatasi dalam hal memperoleh pendidikan, kesehatan, pekerjaan dan sebagainya.

Kesalahan penerjemahan menurut Colina (2015) dipengaruhi oleh faktor budaya seperti variasi bahasa, dialek, tingkat formalitas dan sebagainya. Akan tetapi tak dapat dipungkiri bahwa faktor kemampuan penerjemah dalam penguasaan dwi bahasa dan dwi budaya menjadi salah satu faktor yang mempengaruhi terjadinya kesalahan penerjemahan (Newmark, 1991; Reiss, 2000).

Kesalahan terjemahan dapat terjadi pada level-level tertentu (Zhang, 2016). Pertama pada level kosakata, ini terjadi akibat hal-hal yang tertentu seperti yang telah dijelaskan sebelumnya yakni pada pemilihan padanan kosakata. Kemudian pada level gramatika yakni pada level tata bahasa baik pada teks Bsu maupun teks Bsa. Ketiga level suara yang biasanya disebut juga onomatope. Level berikutnya adalah level idiom yang disebabkan perbedaan budaya. Level terakhir adalah level mikro linguistik. Selain itu kesalahan teknis pun dapat menyebabkan terjadinya kesalahan penerjemahan seperti ejaan (Muñoz, 2012). Selain itu kesalahan dapat terjadi akibat teknik terjemahan yang digunakan.

Molina dan Albir memperkenalkan dua belas teknik terjemahan yakni reduksi (reduction) atau disebut juga omisi, amplikasi (amplification) atau parafrasa, adaptasi (adaptation), peminjaman (borrowing), kompensasi (compensation), kreasi diskrusif (discrusive creation), padanan lazim (established equivalence), amplifikasi linguistik (linguistic implification), kompresi linguistik (linguistik compression), modulasi (modulation), partikularisasi (particularization), penerjemahan generalisasi (generalization), penerjemahan harafiah (literal translation), transposisi (transposition), variasi (variation), kalke (calque), substitusi (substitution), dan deskripsi (description) (Amanda Putri, 2018).

Teknik reduksi (reduction) atau disebut juga omisi digunakan untuk menghilangkan kata, frasa atau klausa dengan tidak mendistorsi makna pada terjemahan. Sementara teknik amplikasi (amplification) merupakan teknik terjemahan yang menggunakan parafrasa. Pada penggunaan teknik adaptasi (adaptation), penerjemah menggunakan kesepadanan budaya dalam Bsa untuk menerjemahkan teks Bsu. Selain itu terdapat juga teknik peminjaman (borrowing) yakni dengan meminjam keseluruhan (pure borrowing) atau peminjaman dengan naturlisasi. Berikutnya adalah teknik kompensasi (compensation) dengan mengganti unsur informasi akibat efek stilistika. Teknik kreasi diskrusif (discrusive creation) biasanya menggunakan padanan di luar konteks terjemahan. Berbeda dengan teknik padanan lazim (established equivalence) menggunakan padanan yang lazim digunakan pada Bsa. Teknik amplifikasi linguistik (linguistic implification) digunakan dengan menambah unsur bahasa yang terdapat pada Bsa. Teknik kompresi linguistik (linguistik compression) digunakan dengan mengintisari makna pada proses terjemahannya. Kemudian teknik modulasi (modulation) yang menggubah sudut pandang dalam menerjemahkan teks Bsu. Teknik penerjemahan generalisasi (generalization) merupakan teknik yang menggunakan istilah umum dalam menerjemahkan. Sebaliknya, teknik partikularisasi (particularization) menggunakan terjemahan dengan istilah yang lebih spesifik. Ada pula terjemahan yang dilakukan secara harafiah yang disebut juga dengan teknik penerjemahan harafiah (literal translation). Penerjemahan dengan mengubah struktur dan kategori gramatika adalah teknik transposisi (transposition). 
Sementara penggantian unsur-unsur linguistik atau para linguistik digunakan dalam teknik variasi (variation). Berbeda dengan teknik variasi, teknik substitusi (substitution) mengganti unsur-unsur linguistik menjadi para linguistik atau sebaliknya. Teknik penerjemahan kalke (calque) merupakan teknik penerjemahan yang dilakukan secara harafiah dan struktural. Akan tetapi teknik ini tetap menyisakan unsur-unsur tertentu pada hasil terjemahannya seperti unsur leksikal atau pun unsur struktural. Kemudian teknik terjemahan dengan cara mendeskripsikan sesuatu atau suatu istilah yang disebut dengan teknik deskripsi (description).

Selain itu dari beberapa teori-teori yang dapat digunakan dalam analisis kesalahan terjemahan seperti yang telah dibahas sebelumnya, teori kesepadanan yang diperkenalkan oleh Baker (2011) dapat pula dijadikan salah satu cara menganalisis kesalahan. Ada tingkatan kesepadanan tersebut yakni tingkat kata, tingkat di atas kata, kesepadanan gramatika, kesepadanan tekstual, dan kesepadanan pragmatis. Pada tingkat kata, analisis kesalahan dapat dilakukan berdasarkan padanan kata yang dipilih. Sementara pada tingkat di atas kata, analisis kesalahan dilakukan pada kategori idiom, kolokasi dan ekspresi tetap (fixed expression). Pada kesepadanan gramatika, sistem kala, orang, bilangan, dan gender dijadikan acuan dalam menganalisis. Pada kesepadanan tekstual, analisis dilakukan pada struktur informasi dan tematik serta kohesi dan koherensi. Pada kesepadanan terakhir yakni kesepadanan pragmatis, analisis kesalahan dapat dilakukan pada implikatur percakapan yang nantinya menjadi dasar munculnya teori maksim. Kelima tingkatan ini dapat dianalisis satu persatu untuk menemukan kesalahan dan permasalahan dalam penerjemahan.

\section{B. METODE}

Pendekatan kualitatif digunakan dalam penelitian ini yakni dengan menjabarkan temuan penelitian secara deskriptif. Sementara teknik analisis data menggunakan analisis isi (content anlysis). Jenis analisis isi yang digunakan adalah analisis percakapan (conversational analysis) oleh Krippendorff (2004). Percakapan yang dimaksud berasal dari dailog tokohtokoh pada film The Help dan Hidden figures. Akan tetapi data yang digunakan adalah subtitle film The Help dan Hidden figures yang diterjemahkan oleh penerjemah film-film secara online dan belum diketahui kemampuannya dalam menerjemahkan teks. Data tersebut berupa dialog yang mengandung unsur budaya pada aspek diskriminasi ras dan gender.

\section{PEMBAHASAN}

Adapun temuan penelitian, terdapat empat jenis kesalahan penerjemahan yang ditemukan pada penerjemahan subtitle film The Help dan Hidden figures yang mengakibatkan terjadinya distorsi makna percakapan. Kesalahan tersebut dapat dilihat pada tabel di bawah ini.

Tabel 1. Data Kesalahan Penerjemahan

\begin{tabular}{clc}
\hline No. & Bentuk Kesalahan & Jumlah Data \\
\hline 1 & $\begin{array}{l}\text { Kesalahan padanan } \\
\text { kata }\end{array}$ & 3 \\
2 & $\begin{array}{l}\text { Kesalahan terjemahan } \\
\text { bilangan }\end{array}$ & 2 \\
3 & $\begin{array}{l}\text { Kesalahan terjemahan } \\
\text { budaya material } \\
\text { Kesalahan memahami } \\
\text { teks Bsu }\end{array}$ & 5 \\
\hline
\end{tabular}

\section{Kesalahan Padanan Kata}

\section{Data 1}

Tsu: We now require advanced extension courses through the University of Virginia. It's in the employee handbook. In addendum

Tsa: Baik, kami sekarang mensyaratkan pelatihan lanjutan untuk lulusan University of 
Virginia. Ini ada di buku pedoman pegawai. Sebuah tambahan.

Menurut penjelasan Oxford Dictionary, kata addendum adalah a section of extra information that is added especially to a book. Sementara dalam KBBI kata addendum adalah kata serapan dari bahasa asing dan terdapat dalam kelas kata nomina addendum memiliki dua makna leksikal yakni lampiran atau jilid tambahan pada buku. Pada penerjemahan Tsu ke dalam Tsa, kata addendum diterjemahkan dengan tidak tepat dengan menggunakan 'sebuah tambahan' sebagai padanan kata addendum. Makna yang terdapat padanan kata tersebut tidak dapat dipahami oleh pembaca. Hal ini menyebabkan makna addendum tidak tersampaikan kepada pembaca Tsa.

Berdasarkan konteks kata addendum pada percakapan di atas, kata tersebut memiliki kesamaan padanan makna dengan kata 'lampiran' pada makna kata addendum dalam KBBI. Hal ini disebabkan kata tersebut memiliki korelasi dengan keterangan in the employee bandbook pada kalimat utuh It's in the employee handbook. In addendum.

Kata addendum merupakan informasi penting dalam percakapan diskriminasi ras pada subtitle film The Hidden Figures. Kata ini memberikan informasi mengenai persyaratan tambahan bagi para insinyur berkulit hitam untuk mengikuti program pelatihan insinyur di NASA yang dibuat petinggi NASA yang berkulit putih. Kata addendum mengisyaratkan adanya penjegalan yang dilakukan oleh orangorang kulit putih terhadap karier orang yang berasal dari keturunan imigran Afrika dan yang memiliki kondisi fisik yang berbeda dari masyarakat kulit putih.

Penjegalan ini mengakibatkan kesempatan untuk memperluas pengetahuan dan berkontribusi bagi bangsa dan negara dalam bidang-bidang tertentu pun terbatas.

\section{Data 2}

Tsu: I'm just going to bave to tell Hilly I ain't no boyfriend stealer.

Tsa: Akan ku beritahu Hilly aku bukanlah pencuri suami orang.

Menurut Oxford Dictionary kata boyfriend memiliki makna a man or boy that someone has a romatic or sexual relationship with. Sementara kata 'suami' dipakai pada seorang pria yang memiliki ikatan perkawinan pada seorang perempuan. Pada konteks percakapan di atas, mitra tutur mengungkapkan fakta bahwa penutur tidak disukai sekelompok wanita yang ia temui karena penutur dianggap sebagai 'sampah' masyarakat. Anggap ini muncul karena adanya fakta penutur hamil sebelum menikahi sang suami yang merupakan pujaan hati semua wanita di Jackson. Konteks boyfriend terjadi sebelum penutur menikahi suaminya. Sehingga penggunaan padanan 'suami' tidak tepat pada terjemahan Tsa. Hal ini menunjukkan bahwa penerjemah tidak memilih padanan kata yang tepat baik secara leksikal maupun kontekstual.

Dalam konteks budaya, frasa boyfriend stealer berkonotasi negatif begitu pula dalam terjemahannya, yakni 'pencuri suami orang'. Dalam masyarakat imigran Amerika tahun 1960, frasa pencuri suami orang menyatakan bahwa perempuan yang melakukannya adalah perempuan hina yang tidak taat agama. Sementara pada masyarakat Indonesia 'pencuri suami orang', yang saat ini terkenal dengan akronim pelakor, dilabelkan pada wanita yang memiliki pasangan suami orang lain. Hubungan tersebut dilakukan secara diam-diam dan apabila diketahui oleh masyarakat maka akan perempuan tersebut bukan hanya mendapat sanksi sosial namun juga sanksi pidana. 


\section{Kesalahan Penerjemahan Bilangan}

\section{Data 3}

Tsu: All the boys say I'm ugly. Mama was third runner-up in the Miss South Carolina pageant.

Tsa: Semua teman pria bilang aku jelek. Sementara ibu juara dua pemilihan Miss Carolina Selatan.

Kontes kecantikan telah dimulai sejak lama. Hal ini dilakukan guna menunjukkan peran perempuan pada bidang sosial, pendidikan dan bidang-bidang lain. Kontes ini biasanya akan memilih satu pemenang dengan beberapa juara tambahan seperti runner-up. Setiap kontes kecantikan telah menentukan jumlah runner-up kontes tersebut, seperti pada kontes kecantikan Putri Indonesia yang terdapat satu juara dan tiga orang runner-up, yakni first runner up, second runner-up, third runner-up. Pada terjemahan diatas, ibu penutur memenangkan kontes kecantikan Miss South Carolina. Akan tetapi, penerjemahan pada third runner-up tidak diterjemahkan dengan tepat, yakni 'juara dua'. Padahal pada konteks terjemahan third runner-up yang pada bilangan ordinal ada pada 'juara ketiga' namun karena pemenang kontes Miss South Carolina termasuk dalam jajaran pemenang maka seharusnya terjemahannya menjadi 'juara empat'. Penerjemahan bilangan pada terjemahan di atas membantu pembaca memahami stereotip terhadap standar kecantikan dalam kompetisi pemilihan putri-putri dalam ajang kontes kecantikan.

\section{Data 4}

Tsu: They are never gonna allow a colored woman to just take classes at an all-white school.

Tsa: Mereka takkan mengizinkan wanita kulit hitam mengikuti kelas di semua sekolah kulit putih!

Terjemahan an all-white school menjadi 'semua sekolah kulit putih' tidaklah tepat.
Hal ini disebabkan adanya unsur bilangan tunggal pada nomina all-white school, yakni an. Kata an menyatakan jumlah tunggal pada kata all-white school tidak diterjemahkan sehingga menyebabkan pergeseran makna menjadi Tsu menjadi 'semua sekolah kulit putih'. Kalimat yang seharusnya mengandung makna 'sebuah sekolah yang hanya menerima kulit putih' tidak tersampaikan dengan baik pada kalimat terjemahan Tsa sehingga unsur budaya dan pesan yang terdapat di dalamnya tidak tersampaikan. An all-white school pada masa itu adalah sekolah yang hanya boleh dimasuki oleh warga kulit putih. Sementara untuk warga kulit hitam, pemerintah mendirikan sekolah yang terpisah. An all-white school adalah sekolah yang memiliki fasilitas lengkap dengan pengajar yang berkualitas. Jurusan yang terdapat dalam pendidikan an all-white school pun beragam tidak seperti sekolah bagi warga kulit hitam. Kondisi ini terjadi karena stereotip pada masa itu terhadap warga kulit hitam yang memiliki label sebagai orang-orang yang membawa penyakit tertentu akibat warna kulit. Hal ini menunjukkan terjadinya diskriminasi dengan membatasi akses pendidikan bagi warga kulit hitam.

\section{Kesalahan Terjemahan Budaya Material}

Data 5

Tsu: You'll be able to wear heels tonight. You're not leaving the house in those anful Mexican man shoes.

Tsa: Kau bisa pakai sepatu hak tinggi. Kau tak boleh tinggalkan rumah dengan sepatu dari Mexico itu.

Pemahaman budaya dalam penerjemahan budaya sangat penting untuk membantu penerjemah memahami konteks terjemahan. Pada terjemahan awful Mexican man shoes, penerjemah menerjemahkan menjadi 'sepatu dari Mexico'. Sementara 
maksud penutur awful Mexican man shoes adalah sepatu tanpa hak yang dipakai perempuan. Sepatu ini mirip dengan sepatu pantofel yang dipakai pria dan akan tidak layak ketika digunakan untuk menemui seorang pria dalam sebuah kencan buta. Adapun gambar anful Mexican man shoes yang dimaksud dapat dilihat pada gambar di bawah ini.

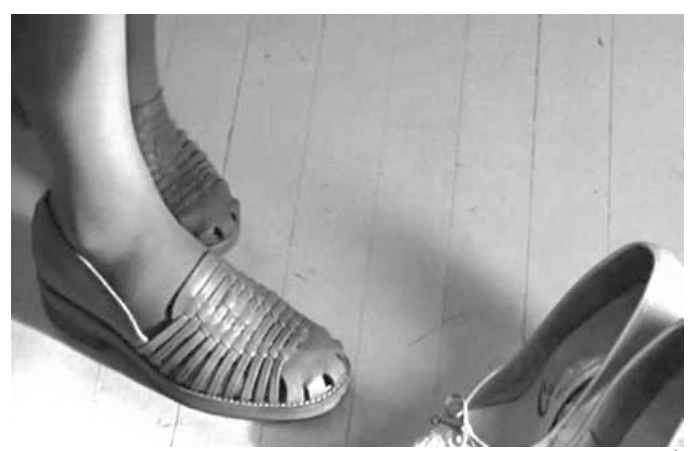

Gambar 1. Awful Mexican Man Shoes ${ }^{1}$

\section{Kesalahan Memahami Teks Bsu}

\section{Data 6}

Tsu: It's what we dream of doing all weekend long. Get back into they house, polish the silver.

And we just love not making minimum wage or getting Social Security.

Tsa: Ini yang kami impikan sejak lama. Kembali ke rumah mereka, membersihkan perkakas perak. Dan kami senang dapat gaji di bawah UMR ataupun Kartu Jaminan Sosial.

Penerjemahan kalimat We just love not making minimum wage or getting Social Security diterjemahkan menjadi 'kami senang dapat gaji di bawah UMR ataupun Kartu Jaminan Sosial' di mana terdapat kesalahan penerjemah dalam menerjemahkan kalimat Tsu tersebut. Pada Tsu terdapat kata not sebelum frasa minimum wage. Berdasarkan penggunaan kata not pada kalimat tersebut, seharusnya kalimat terjemahan Bsa menjadi 'tidak dapat upah minimun' atau dengan kata lain para pembantu mendapatkan upah yang tinggi. Akan tetapi pemahaman penerjemah pada kalimat tersebut mengakibatkan pergeseran makna yang disebabkan oleh kesalahan dalam menerjemahkan teks Tsu.

Frasa minimum wage merupakan frasa yang menunjukkan sistem penggaiian yang dilakukan bagi buruh kulit hitam. Hal ini pun menunjukkan adanya sistem yang sama yang dianut oleh masyarakat Indonesia dan Amerika dalam penetapan sistem upah. Meskipun demikian perbedaan juga terdapat di dalamnya, yakni pada penetapan jumlahnya.

\section{Data 7}

Tsu:

A: It's not Jackson. And that book is garbage. I bet the whole thing is made up by some nigra. And Jolene, didn't your mama leave Cora to you in her will?

B: Yes, but that's not odd, is it? Happens all the time, right?

Tsa:

A: Ini bukan warga Jackson. Dan buku itu sampah. Aku yakin semua itu dikarang oleh kulit hitam. Dan Jolene, bukankah ibumu...meninggalkan Cora untukmu di dalam wasiatnya?

B: Ya, bukankah itu aneh? Sering terjadi, ya?

Pada penerjemahan kalimat retorik, penerjemah menerjemahkan kalimat tersebut dengan tidak tetap. Hal ini dipengaruhi faktor kelaziman pada kalimat retorika dalam Tsa yang memakai kata bukankah. Akan tetapi hal ini mengakibatkan pergeseran makna kalimat Yes, but that's not odd, is it? Happens all the time, right? menjadi 'Ya, bukankah itu aneh? Sering terjadi, ya?'. Kalimat that's not odd diterjemahkan menjadi 'bukankah aneh'. Padahal seharusnya diterjemahkan

${ }^{1}$ https://www.google.com/search?q $=$ mexican + man + shoes\&safe 
menjadi bukankah itu biasa dengan penggunaan teknik modulasi untuk menyatakan kelaziman memasukkan pembantu kulit hitam sebagai salah satu warisan yang bisa diberikan pada keturunan majikan. Lalu kalimat Happens all the time, right? menjadi 'Sering terjadi, ya?' memberikan pergeseran makna. Tsu menggunakan kata right untuk nada persetujuan sementara pada penggunaan kata ya kalimat menjadi bernada konfirmasi.

\section{PENUTUP}

Analisis kesalahan terjemahan pada artikel penelitian ini menggunakan teori kolaborasi oleh beberapa ahli dalam menemukan dan menganalisis kesalahan terjemahan. Berdasarkan analisis terjemahan budaya dalam subtitle film The Help dan Hidden Figures pada aspek diskriminasi ras dan gender ditemukan empat kesalahan yang dilakukan penerjemah. Kesalahan meliputi kesalahan dalam pemilihan padanan kata, kesalahan penerjemahan budaya material, kesalahan penerjemahan bilangan dan kesalahan dalam memahami teks. Kesalahan di atas mempengaruhi kualitas penerjemahan. Ketidaktepatan terjemahan mengakibatkan informasi yang disampaikan tidak lengkap dan cenderung tidak benar. $\mathrm{Hal}$ ini tentunya sangat merugikan penonton yang mengakses informasi lintas budaya khususnya pada aspek diskriminasi ras dan gender.

\section{DAFTAR PUSTAKA}

Amanda Putri, D. (2018). Audio-Visual Translation: Subtitling and Dubbing Technique-Movie Soundtrack in Frozen: Let it Go. XXIV(2), 381-398.

Arsi, M., \& Sobur, A. (2019). Makna Identitas Budaya dan Konflik Antaretnis dalam Film "Crazy Rich Asians ." 12(1), 46-60.

Baker, M. (2011). In Other Words. New York: Routledge.
Clair, M., \& Denis, J. S. (2015). Racism, Sociology of. International Encyclopedia of the Social \& Behavioral Sciences: Second Edition, 19, 857-863. https://doi.org/10.1016/B978-0-08097086-8.32122-5

Colina, S. (2015). Fundamentals of Translation. Cambridge: Cambrige University Press.

Geng, X. (2013). Techniques of the Translation of Culture. Theory and Practice in Language Studies, 3(6), 977981.

https://doi.org/10.4304/tpls.3.6.977 $-981$

Guo, H. (2012). A Brief Analysis of Culture and Translation. Theory and Practice in Language Studies, 2(2), 343347.

https://doi.org/10.4304/tpls.2.2.343 $-347$

Hatim, B., \& Munday, J. (2013). Summary for Policymakers. In Climate Change 2013 - The Physical Science Basis (Vol. 53).

https://doi.org/10.1017/CBO97811 07415324.004

Kramsch, C. (2008). Language and Culture. UK: Oxford University Press.

Krippendorff, K. (2004). Content Analysis: An Introduction to Its Methodology (2nd Editio). New Dehli: Sage Publications, Inc.

Muñoz, I. D. (2012). Analysing common mistakes in translations of tourist texts ( Spanish, English and German) *. 26, 335-349.

Naserly, M. K. (2017). Terjemahan Aspek Budaya Dalam Subtitle Film Date Night. IX(2), 173-181.

Newmark, P. (1986). Approaches to Translation. London: Pregamon Press.

Newmark, P. (1988). a Textbook of Translation. UK: Prentice Hall.

Newmark, P. (1991). About Translation. Avon: Multilingual Matters Ltd.

Nurmila, N. (2015). Pemahaman Agama Dan Pembentukan Budaya. (105), 1-16.

Pourkalhor, O., \& Esfandiari, N. (2017). 
Culture in Language Learning: Background, Issues and Implications. 2332.

Reiss, K. (2000). No TitleTranslation CritismThe Potentials \& Limitations. UK: ST. Jerome Publishing.

Sokolovsky, Y. V. (2010). On the Linguistic Definition of Translation. Humanities \& Social Sciences, 2(2010 3), 285-292. Diambil dari http://sangu.edu.ge/books/hum/on sґдазбъдмœбјмдs/13_sokolovski y.pdf

Zhang, L. (2016). Error Analysis of Business English Translation Based upon Functional Theory. Advances in Literary Study, 04(03), 37-40. https://doi.org/10.4236/als.2016.43 007 